\title{
Genomic insights into temperature-dependent transcriptional responses of Kosmotoga olearia, a deep-biosphere bacterium that can grow from 20 to $79{ }^{\circ} \mathrm{C}$
}

\author{
Stephen M. J. Pollo ${ }^{1}$ Abigail A. Adebusuyi ${ }^{1,5}$ • Timothy J. Straub ${ }^{2,6}$ • \\ Julia M. Foght ${ }^{1} \cdot$ Olga Zhaxybayeva $^{2,3} \cdot$ Camilla L. Nesbø $^{1,4}$
}

Received: 6 June 2017 / Accepted: 11 August 2017 / Published online: 11 September 2017

(c) The Author(s) 2017. This article is an open access publication

\begin{abstract}
Temperature is one of the defining parameters of an ecological niche. Most organisms thrive within a temperature range that rarely exceeds $\sim 30^{\circ} \mathrm{C}$, but the deep subsurface bacterium Kosmotoga olearia can grow over a temperature range of $59^{\circ} \mathrm{C}\left(20-79^{\circ} \mathrm{C}\right)$. To identify genes correlated with this flexible phenotype, we compared transcriptomes of $K$. olearia cultures grown at its optimal $65^{\circ} \mathrm{C}$ to those at 30,40 , and $77^{\circ} \mathrm{C}$. The temperature treatments affected expression of 573 of 2224 K. olearia genes. Notably, this transcriptional response elicits re-modeling of the cellular membrane and changes in metabolism, with increased expression of genes involved in energy and carbohydrate metabolism at high temperatures and up-regulation of amino
\end{abstract}

Communicated by L. Huang.

Electronic supplementary material The online version of this article (doi:10.1007/s00792-017-0956-9) contains supplementary material, which is available to authorized users.

Camilla L. Nesbø

nesbo@ualberta.ca

1 Department of Biological Sciences, University of Alberta, Edmonton, AB, Canada

2 Department of Biological Sciences, Dartmouth College, Hanover, NH, USA

3 Department of Computer Science, Dartmouth College, Hanover, NH, USA

4 Centre for Ecological and Evolutionary Synthesis, Department of Biology, University of Oslo, Oslo, Norway

5 Present Address: Vancouver Island University, Nanaimo, BC, Canada

6 Present Address: Genomic Center for Infectious Diseases, Broad Institute, Cambridge, MA, USA acid metabolism at lower temperatures. At sub-optimal temperatures, many transcriptional changes were similar to those observed in mesophilic bacteria at physiologically low temperatures, including up-regulation of typical cold stress genes and ribosomal proteins. Comparative genomic analysis of additional Thermotogae genomes indicates that one of $K$. olearia's strategies for low-temperature growth is increased copy number of some typical cold response genes through duplication and/or lateral acquisition. At $77{ }^{\circ} \mathrm{C}$ onethird of the up-regulated genes are of hypothetical function, indicating that many features of high-temperature growth are unknown.

Keywords Thermotogae $\cdot$ RNA-Seq $\cdot$ Lateral gene transfer $\cdot$ Temperature response $\cdot$ Cold response $\cdot$ Thermal adaptation

\section{Introduction}

Microorganisms are capable of growing over an impressive temperature range, at least from -15 to $122{ }^{\circ} \mathrm{C}$ (Takai et al. 2008; Mykytczuk et al. 2013), and temperature is one of the most important physical factors determining their distribution, diversity, and abundance (Schumann 2009). However, individual microbial species grow only within a much narrower temperature interval. For example, Escherichia coli O157:H7 thrives in the laboratory between 19 and $41{ }^{\circ} \mathrm{C}$ (Raghubeer and Matches 1990), while Geobacillus thermoleovorans has a growth range of $37-70{ }^{\circ} \mathrm{C}$ (Dinsdale et al. 2011). Microorganisms with temperature ranges $>50{ }^{\circ} \mathrm{C}$ are rare and, to date, research into the few that have ranges $>40{ }^{\circ} \mathrm{C}$ has focused on psychrophiles (e.g., Mykytczuk et al. 2013). Kosmotoga olearia TBF 19.5.1 (hereafter referred to as $K$. olearia) is an anaerobic thermophile from the bacterial 
phylum Thermotogae with a growth range that spans almost $60{ }^{\circ} \mathrm{C}$ (DiPippo et al. 2009). How does this organism achieve such physiological flexibility, and what are the evolutionary advantages and implications of this capability?

Fluctuations in temperature induce broad physiological changes in cells, including growth rate, alterations to cell wall and membrane composition, translation, and energy metabolism (Barria et al. 2013; Pollo et al. 2015; Schumann 2009). These physiological changes can be classified into two broad types of cellular response. Cold or heat shock designates the changes observed immediately after the shift of a culture to a lower or higher temperature, while prolonged growth at a specific lower or higher temperature elicits an acclimated low- or high-temperature response (Barria et al. 2013; Schumann 2009). Most studies of prokaryotes have focused on temperature shock responses rather than acclimated growth. Among the Thermotogae, responses to both heat shock and prolonged growth at high temperatures have been studied in the hyperthermophile Thermotoga maritima, which can grow between 55 and $90{ }^{\circ} \mathrm{C}$ (Pysz et al. 2004; Wang et al. 2012). During prolonged high-temperature growth, $T$. maritima strongly up-regulates central carbohydrate metabolism genes and expresses a few typical heat shock protein genes (Wang et al. 2012). Little is known about how T. maritima responds to sub-optimal temperatures, although it encodes some genes implicated in cold shock response. For example, its family of cold shock proteins (Csp), which are nucleic acid chaperones known to be induced during cold shock and cold acclimation in mesophilic bacteria (Barria et al. 2013; Phadtare 2004), exhibits nucleic acid melting activity at physiologically low temperatures (Phadtare et al. 2003). Similarly, responses to cold shock in a few other thermophiles involve many of the genes implicated in mesophilic cold shock response (e.g., Boonyaratanakornkit et al. 2005; Mega et al. 2010). In this study, we systematically assessed bacterial physiological changes associated with response to prolonged growth at both high and low temperatures using $K$. olearia as a model system. Such changes can reflect not only response to temperature itself, but also growth rate effects and general responses to stress. By conflating these factors, our study examined overall changes in $K$. olearia's gene expression in the environments defined by a specific temperature.

$K$. olearia was isolated from a deep subsurface oil reservoir with in situ temperature of $68{ }^{\circ} \mathrm{C}$ (DiPippo et al. 2009). Cultivation experiments, $16 \mathrm{~S}$ rRNA surveys, and metagenomic analyses have confirmed that the principal natural habitat of $K$. olearia is deep subsurface sediments and that these bacteria are particularly abundant in hightemperature petroleum reservoirs (e.g., Vigneron et al. 2017; Duncan et al. 2009; Gittel et al. 2009; Pollo et al. 2016; Nesbø et al. 2010; Kotlar et al. 2011). However, $K$. olearia has also been either isolated or detected via $16 \mathrm{~S}$ rRNA sequencing in oil fields (Nesbø et al. 2010), in an underground salt cavern plant used to store oily sand (Bordenave et al. 2013), and in engineered systems (Duncan et al. 2014; Oko et al. 2017) with in situ temperatures of $20-50{ }^{\circ} \mathrm{C}$, indicating that this bacterium occupies an ecological niche defined by a broad temperature range.

The $K$. olearia genome (NC_012785) has 2,302,126 bp and is predicted to encode 2224 genes (Swithers et al. 2011). Within the Thermotogae, genome size, intergenic region size, and number of predicted coding regions correlate with the optimal growth temperature of an isolate (Zhaxybayeva et al. 2012), with hyperthermophilic Thermotogae genomes being the most compact. Phylogenetically, the Thermotogae order Kosmotogales comprises the genera Kosmotoga and Mesotoga spp., the latter being the only described mesophilic Thermotogae lineage (Pollo et al. 2015). Assuming a hyperthermophilic last common ancestor of the Thermotogae (Zhaxybayeva et al. 2009), the Kosmotogales can be hypothesized to have acquired wide growth temperature tolerance secondarily by expanding its gene repertoire. Moreover, it is likely that the ability of the Kosmotogales common ancestor to grow at low temperatures enabled the evolution of mesophily in Mesotoga (Pollo et al. 2015).

Such adaptations to novel environments can be greatly facilitated by lateral gene transfer (LGT), since genes already "adapted" to the new conditions are readily available in the microbial communities of the new environment (Boucher et al. 2003). For instance, LGT has been implicated in adaptation to high-temperature growth in hyperthermophilic bacteria, including Thermotoga spp., and to low-temperature growth in archaea (López-García et al. 2015; Pollo et al. 2015; Boucher et al. 2003). Genome analysis of the mesophilic Mesotoga prima revealed that it laterally acquired $32 \%$ of its genes after it diverged from other Thermotogae (Zhaxybayeva et al. 2012). Many of the predicted gene donors are mesophiles, supporting the importance of lateral acquisition of genes already adapted to mesophilic conditions in the evolution of Mesotoga.

To further gain insights into mechanisms of bacterial temperature response, we sequenced 13 transcriptomes from isothermal cultures of $K$. olearia and examined transcriptional differences at temperatures spanning its wide growth range $\left(30,40,65\right.$, and $\left.77^{\circ} \mathrm{C}\right)$. We also investigated the importance of gene family expansion for adaptation of $K$. olearia to growth over a wide temperature range via comparative genomic and phylogenetic analyses of identified temperature-responsive genes and their homologs in two newly sequenced Kosmotoga isolates, as well as in genomes of other thermophilic and mesophilic Thermotogae. 


\section{Results}

\section{Temperature shifts and isothermic conditions elicit different growth patterns in $K$. olearia}

Under laboratory conditions in liquid anaerobic medium, we observed growth of $K$. olearia at temperatures as low as $25{ }^{\circ} \mathrm{C}$ and as high as $79{ }^{\circ} \mathrm{C}$, with optimal growth at $65{ }^{\circ} \mathrm{C}$, defined as the temperature affording the fastest growth rate (Fig. 1, Fig. S1). Using a non-linear regression model (Ratkowsky et al. 1983), we estimate a growthpermissive temperature range of $20.2-79.3{ }^{\circ} \mathrm{C}$, consistent with the previously reported wide growth range of this isolate (DiPippo et al. 2009). Interestingly, we were not able to cultivate $K$. olearia at temperatures near its range boundaries $\left(30\right.$ and $77{ }^{\circ} \mathrm{C}$ ) by direct transfer from $65^{\circ} \mathrm{C}$ cultures. Instead, the growth temperature had to be changed sequentially in $\leq 10{ }^{\circ} \mathrm{C}$ increments. Particularly at the extremes, even small temperature shifts caused both a longer lag phase and a slower growth rate compared to isothermal cultures (Fig. 1, Fig. S1). This phenomenon has been previously noted for mesophilic bacteria, especially for transitions from high to low temperature (Swinnen et al. 2004). Our observations suggest that cells shifted to a new temperature need to undergo large physiological changes that require time [i.e., an 'acclimation' period (Barria et al. 2013)], and that these physiological challenges are too great to overcome when temperature changes are large.

\section{Architecture of the K. olearia transcriptome}

Analysis of transcription start and stop sites predicted a minimum of 916 transcriptional units (TU) in K. olearia (Supplemental material and Table S2), 52\% of which consist of a single gene. This fraction of single-gene TUs lies between the 65\% reported for E. coli (Cho et al. 2009) and the $43 \%$ recorded for T. maritima, which has also been shown to have a streamlined genome and a low-complexity transcriptome (i.e., few sub-operonic transcripts and few genes with multiple start sites) (Latif et al. 2013). The average TU length of $\sim 2.39$ genes in $K$. olearia is less than the 3.3 genes per transcript of T. maritima (Latif et al. 2013) but closer to 2.2 genes per transcript in the mesophilic firmicute Geobacter sulfurreducens (Qiu et al. 2010) and 1-2 genes per transcript in bacteria in general (e.g., Cho et al. 2009). Given that the $K$. olearia genome has more intergenic DNA than T. maritima's genome (the ratio of the nucleotides located in noncoding vs coding regions is 0.13 in $K$. olearia and 0.06 in $T$. maritima), the shorter TU lengths in $K$. olearia may point to more flexible transcriptional regulation.

\section{Consistent energy generation across different temperature conditions}

$K$. olearia produces ATP from pyruvate using a biochemically well-understood fermentation pathway that generates hydrogen, carbon dioxide and acetate (DiPippo et al. 2009; Fig. 2 and data not shown). Since pyruvate was the carbon and energy source provided in all experiments,

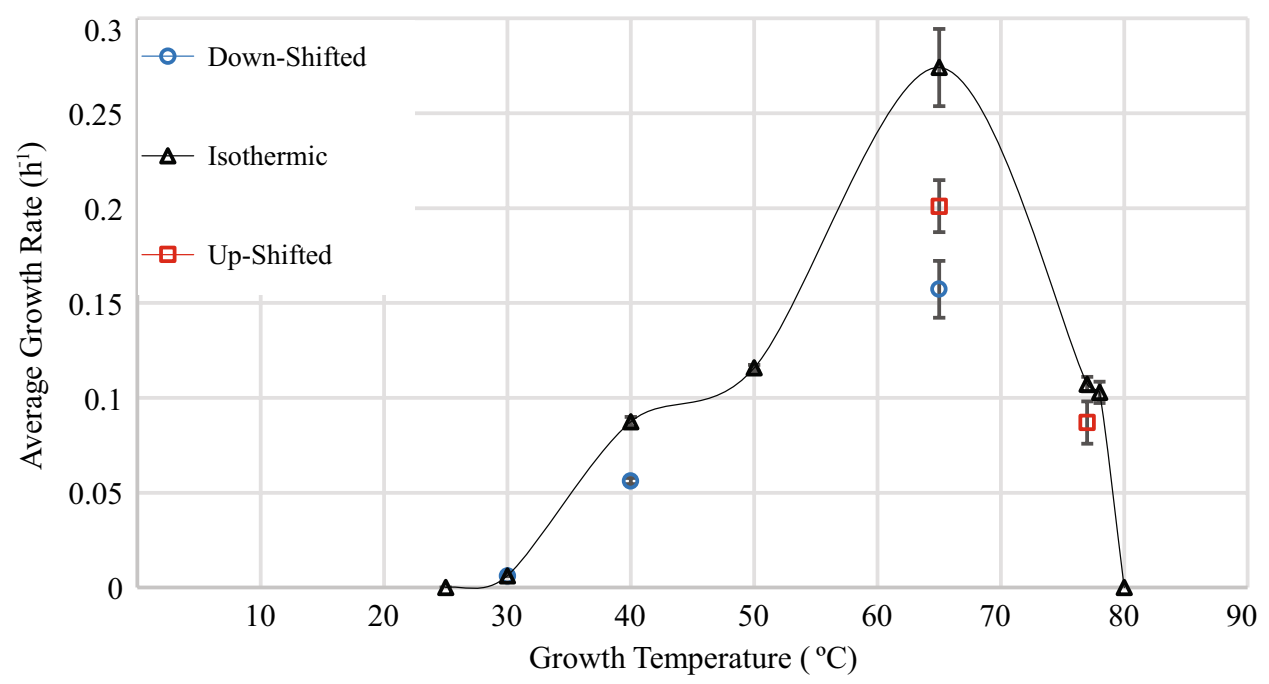

Fig. 1 Growth rate of $K$. olearia as a function of temperature. Isothermic growth curves were generated at each temperature from an inoculum grown at that temperature for at least three transfers (except for 25 and $80{ }^{\circ} \mathrm{C}$, for which an inoculum from the same temperature could not be generated; see "Materials and methods"). Up-shifted and down-shifted growth curves were generated from an inoculum that was grown at lower and higher temperatures, respectively. Red squares growth temperature up-shifted from 65 to $77{ }^{\circ} \mathrm{C}$ or from 40 to $65{ }^{\circ} \mathrm{C}$, blue circles growth temperature down-shifted from 77 to $65{ }^{\circ} \mathrm{C}, 65$ to $40{ }^{\circ} \mathrm{C}$, or 40 to $30^{\circ} \mathrm{C}$. Data points represent the mean of replicate cultures (see "Materials and methods"); error bars represent standard error 


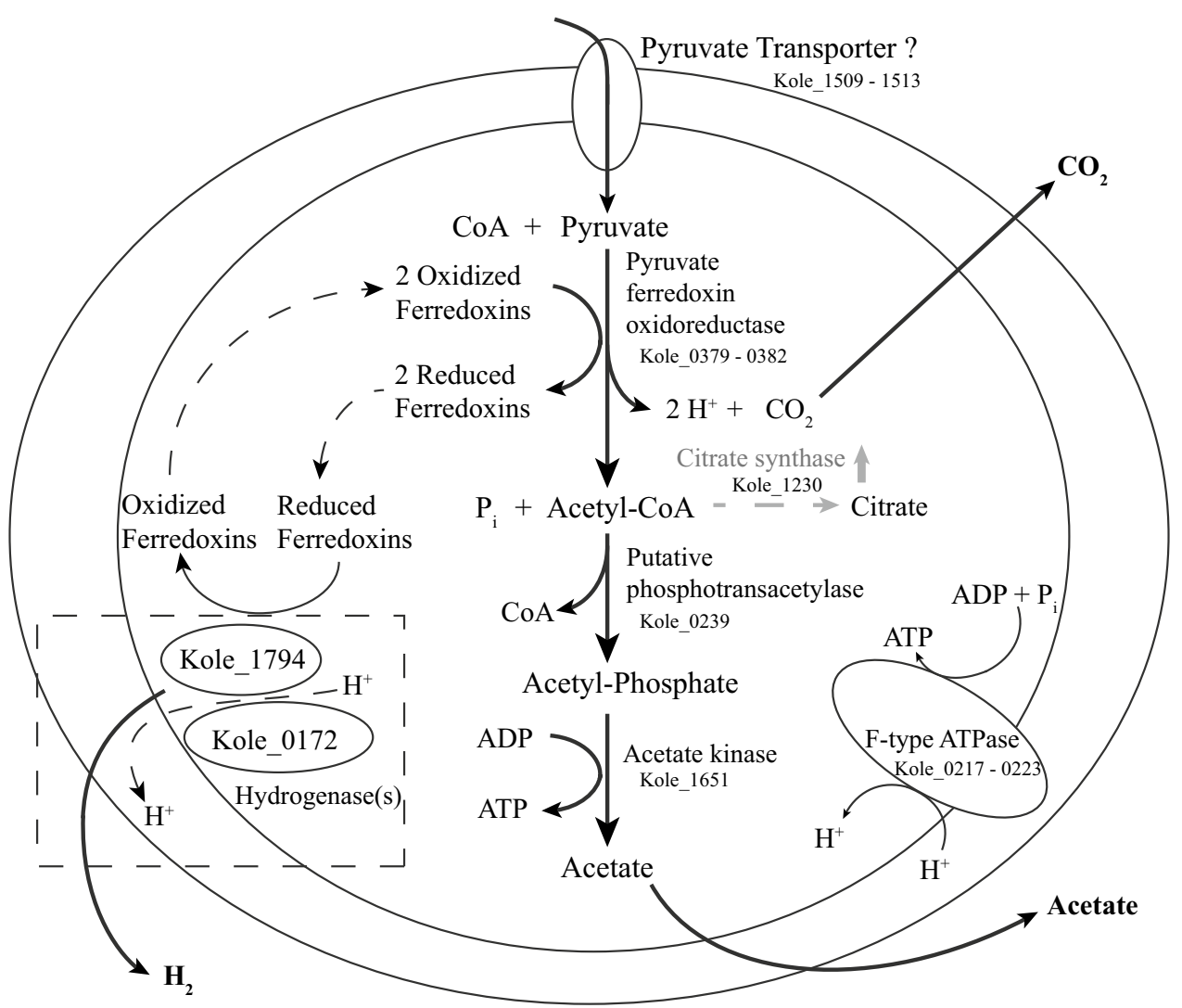

Fig. 2 Model of energy generation pathway in $K$. olearia during growth on pyruvate. The model includes genes likely involved in conversion of pyruvate to acetate, $\mathrm{CO}_{2}, \mathrm{H}_{2}$, and ATP. The genes were selected from the list of genes highly expressed across all temperature conditions (Fig. S2A; Table S3). Acetate transport is not shown. The dashed box indicates hydrogenase activity. The two highly expressed hydrogenases are shown, but their potential interactions with each other or with the membrane are not known. Increased expression of citrate synthase at low temperature, which could redirect acetyl-CoA

we surveyed 51 genes predicted to be involved in core energy metabolism during growth on pyruvate. Based on expression levels, we constructed a model that accounts for all major end products during growth at $65^{\circ} \mathrm{C}$ (Fig. 2) and contains 15 genes with consistently high expression across all temperature treatments (Fig. S2A; Table S3). In addition to indirectly validating the previously known functional annotations of these genes, we furthermore propose that the most highly expressed $\mathrm{ABC}$ transporter gene cluster, Kole_1509-1513, encodes a pyruvate transporter (Fig. 2). Its current annotation as a peptide ABC transporter may be erroneous, since most of the peptide $A B C$ transporters predicted in T. maritima using bioinformatics have been shown instead to bind and transport sugars (Nanavati et al. 2006). Further functional studies of the transporter (e.g., binding assays, expression with different substrates) are needed to confirm this hypothesis. away from acetate production, is shown in gray. The assignment of the $\mathrm{ABC}$ transporter as pyruvate transporter (Kole_1509-1513) is based on its high expression level, but experiments are needed to confirm its involvement in pyruvate transport. The model also explains the observed lower ratio of carbon dioxide to hydrogen produced by growth on maltose vs pyruvate (not shown), because during growth on maltose reduced electron carriers would be generated from the conversions of maltose to pyruvate

\section{Identification of temperature-related transcriptional responses in $K$. olearia}

Hierarchical clustering and principal component analysis (PCA) separated the transcriptomes according to temperature treatment (Fig. 3, Fig. S3 and Supplemental material), suggesting that the observed changes in transcription are due to the culture growth temperature. Several genes with a high correlation between their expression level and a specific growth temperature (Table S4; vectors in Fig. 3) are known to be involved in temperature response (Pollo et al. 2015). For example, expression of the heat shock serine protease Kole_1599 positively correlated with the $77{ }^{\circ} \mathrm{C}$ transcriptomes (Fig. 3), where high expression of this protease was expected based on its involvement in heat shock response in T. maritima (Pysz et al. 2004). Similarly, expression of the cold shock protein genes Kole_0109 and Kole_2064 


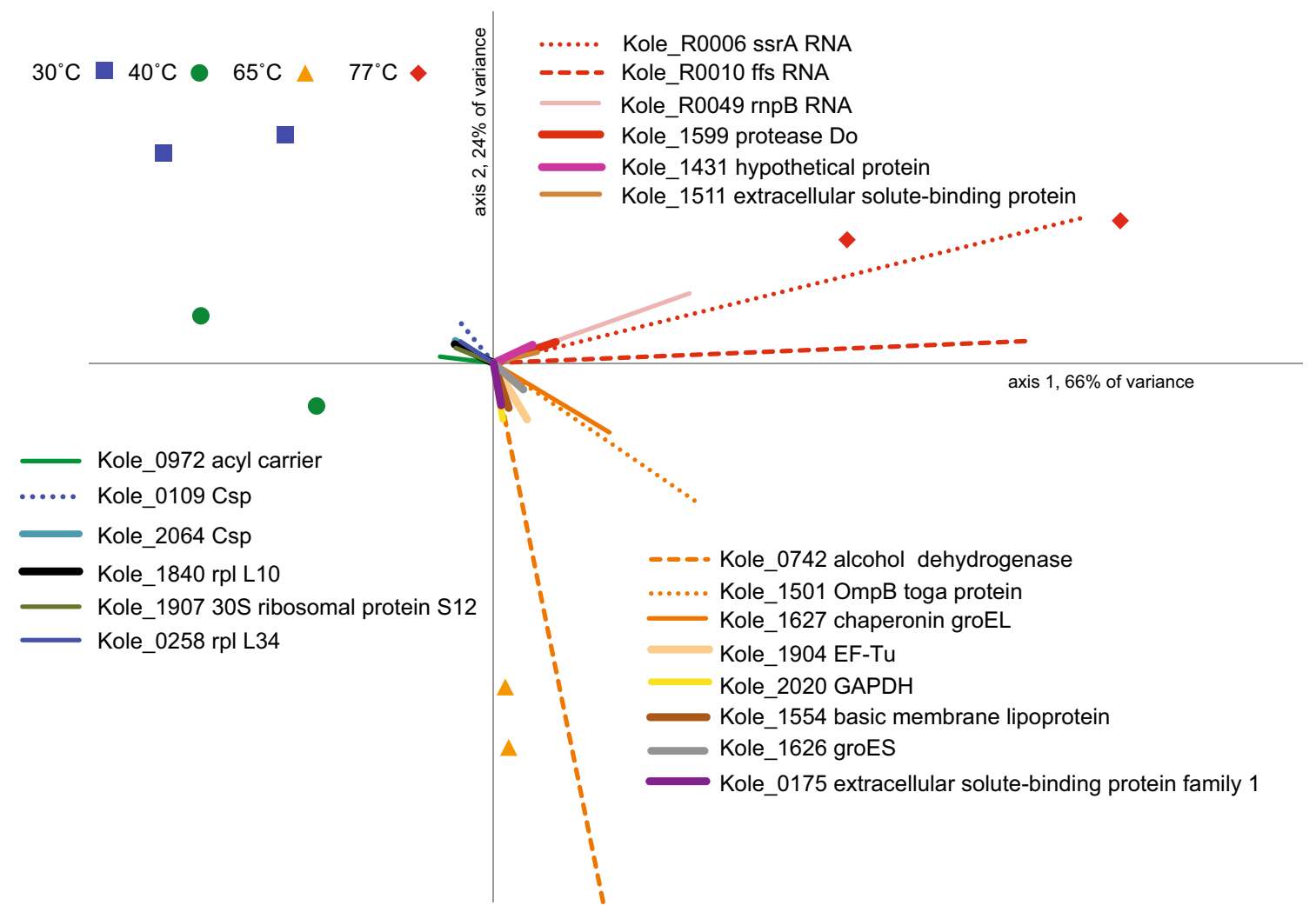

Fig. 3 Biplot of the principal component analysis of 8 transcriptomes. The plot is based on expression values from all genes. Each transcriptome is denoted by a point and genes are represented by vectors. The 20 longest (i.e., most highly correlated) gene vectors are shown. Coordinates and vector length for all genes can be found in Table S4. It should be noted that the ffs (Kole_R0010) transcript is only $115 \mathrm{nt}$, and may not have been fully represented in every transcriptome due to our isolation protocol which selects against small RNA $(<200$ nucleotides). Also, the high expression of the alcohol dehydrogenase (Kole_0742) is probably due to the addition of stop solution before RNA isolation (see Supplemental material)

respectively (Table S5). Expression of 306 of the 573 putative temperature-responsive genes correlated with growth rate $(r>10.71$; Table S5). We used ANCOVA to untangle the effect of growth rate from temperature, which revealed that growth rate was a significant factor for only 60 of the 306 genes $(p<0.05$; Table S5). Moreover, for 26 of these 60 genes temperature was also a significant factor, and the simpler growth-rate-only model was rejected for all but 13 of the 60 genes (Likelihood Ratio Test, FDR-corrected $p$ value $<0.05$; Table S5). In an alternative comparison based on relative effect size of temperature vs growth rate, growth rate had larger influence on expression of 51 of the 306 genes (Table S5). Among these genes were the glyceraldehyde-3-phosphate dehydrogenase (Kole_2020) and the iron-containing alcohol dehydrogenase (Kole_0742) mentioned above. Therefore, although we retained the designation of "putatively temperature-responsive" for all 573 genes, below we focus on genes not primarily affected by growth rate. 


\section{Distribution of temperature-responsive genes across functional categories suggests a regulated response to temperature}

Most of the temperature-responsive genes were up-regulated when compared to the expression at $65^{\circ} \mathrm{C}(155$ genes are down-regulated and 559 up-regulated; Table S5). One notable exception to this overall trend were genes involved in carbohydrate and energy metabolism [Clusters of Orthologous Groups (COG) categories $\mathrm{C}$ and $\mathrm{G}$ ] where 32 genes were down-regulated at $30{ }^{\circ} \mathrm{C}$ compared to 15 genes upregulated. In transcriptomes at all non-optimal temperatures, the list of putative temperature-responsive genes was depleted in genes involved in translation (COG category $\mathrm{J}$ ) and nucleotide metabolism (COG category F) (Fig. 4) and conversely enriched in genes involved in signal transduction (COG category $\mathrm{T}$ ), and replication, recombination and repair (COG category L, particularly at $30{ }^{\circ} \mathrm{C}$ ). Differential expression of the signal transduction genes (COG category $\mathrm{T})$ suggests the importance of these systems for regulating cellular responses at all tested temperatures. Most of the identified COG category L genes are either mobile elements or CRISPR-associated proteins, hinting at an increased activity of mobile genetic elements-a known common feature of stress responses (Foster 2007). Additionally, at both 30 and $77{ }^{\circ} \mathrm{C}$ many genes encoding transcription regulators (COG category $\mathrm{K}$ ) are up-regulated, implying that prolonged growth at sub- and supra-optimal temperatures results in detectable changes in transcriptional gene regulation in $K$. olearia.

\section{At $40{ }^{\circ} \mathrm{C}$ there are pronounced differences} in membrane fatty acid composition but no signs of cold stress

Although the growth rate of $K$. olearia at $40{ }^{\circ} \mathrm{C}$ is only onethird of that at the optimum $65^{\circ} \mathrm{C}$ (Fig. 1, Fig. S1), clustering analysis suggested that the $40{ }^{\circ} \mathrm{C}$ transcriptome was most similar to that at $65^{\circ} \mathrm{C}$ (Fig. 3, Fig. S3). However, at $40{ }^{\circ} \mathrm{C}$ even the four most highly expressed temperature-responsive genes, including the growth-rate dependent alcohol dehydrogenase (Kole_0742), had significantly lower expression levels (Table S5), reflecting the slower metabolic rate at lower temperature growth. Yet, 94 of 115 putative temperature-responsive genes were up-regulated (Table S5; Fig. $\mathrm{S} 2 \mathrm{~B}$ ), suggesting that slower metabolism is not the only

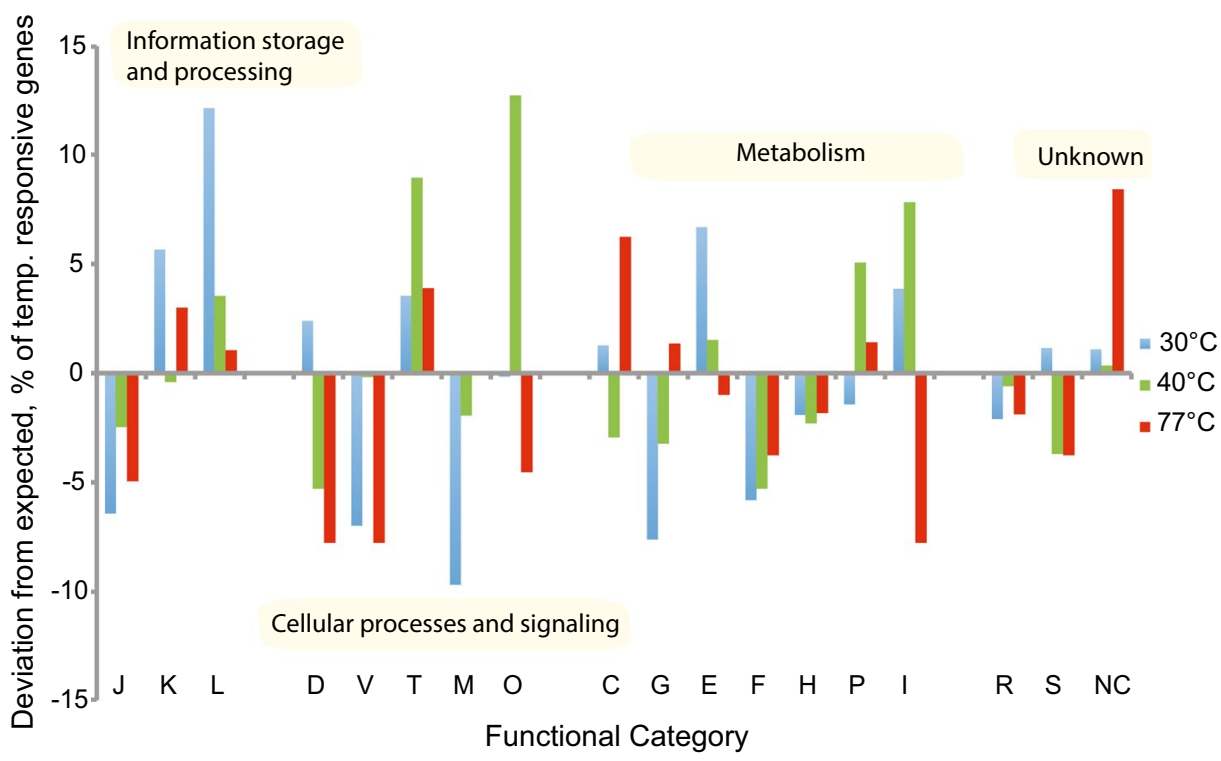

Fig. 4 Difference between observed and expected number of temperature-responsive genes across functional categories. Functional categories were assigned using the COG database as implemented in IMG (Markowitz et al. 2014) and are denoted by one-letter abbreviations along the $X$-axis. For each temperature treatment (30, 40 and $77{ }^{\circ} \mathrm{C}$ ), only the temperature-responsive fraction of the $K$. olearia genome was considered. If the temperature-responsive genes were randomly distributed across functional categories, we would expect the same fraction of temperature-responsive genes in each COG category. The difference (in percent) between the observed and expected number of temperature-responsive genes is plotted on the $Y$-axis with positive and negative values referring to over- and under-representa- tion of the temperature-responsive genes, respectively. COG category abbreviations: $J$ translation, ribosomal structure and biogenesis, $K$ transcription, $L$ replication, recombination and repair, $D$ cell cycle control, cell division, chromosome partitioning, $V$ defense mechanisms, $T$ signal transduction mechanisms, $M$ cell wall/membrane/ envelope biogenesis, $O$ post-translational modification, protein turnover, and chaperones, $C$ energy production and conversion, $G$ carbohydrate transport and metabolism, $E$ amino acid transport and metabolism, $F$ nucleotide transport and metabolism, $H$ coenzyme transport and metabolism, $P$ inorganic ion transport and metabolism, $I$ lipid transport and metabolism, $R$ general function prediction only, $S$ function unknown, $N C$ not in COG database 
explanation for the observed transcriptional response to growth at $40{ }^{\circ} \mathrm{C}$.

Lipid metabolism (COG category I) appears to be particularly important at $40^{\circ} \mathrm{C}$. For instance, all the predicted fatty acid synthesis genes showed the highest expression at $40{ }^{\circ} \mathrm{C}$ (Fig. S4), with significantly higher expression of two genes involved in synthesis of unsaturated fatty acids (Kole_0968) and initiation of fatty acid synthesis (Kole_0969). Biochemical analyses of total fatty acids at 40 and $65{ }^{\circ} \mathrm{C}$ showed a much greater diversity of fatty acids at $40{ }^{\circ} \mathrm{C}$ (Table S6), which may explain the higher demand for the products of these genes at lower temperatures. Interestingly, there was increased expression of a phosphate $\mathrm{ABC}$ transporter (Kole_0707-Kole_0711, Table S5; Fig. S2B), which may be linked to increased production of polar membrane lipids at moderately low temperatures.

An enrichment of differentially expressed genes in "posttranslational modification, protein turnover, and chaperone function" (COG category $\mathrm{O}$; the category that harbors genes related to cellular stress) was due to both up- and down-regulation of the involved genes (Fig. 4). For instance, K. olearia has three temperature-responsive peptidylprolyl isomerase (PPIase) genes: two PpiC-type genes (Kole_1682 and Kole_0383) that are both highly expressed at $40{ }^{\circ} \mathrm{C}$, and one FKBP-type gene (Kole_1745) that shows high expression at all temperatures except $77^{\circ} \mathrm{C}$ (Table S5). At lower temperatures (e.g., $37^{\circ} \mathrm{C}$ ), these enzymes catalyze proline isomerization, which happens spontaneously at higher temperatures (Godin-Roulling et al. 2015). However, the enzymes known to assist protein folding under cellular stress, chaperones [GroEL (Kole_1627) and Hsp70 (Kole_0886)] and protease Do (Kole_1599), were significantly down-regulated at $40{ }^{\circ} \mathrm{C}$ (Table S5; Fig. S2B). Among other typical cold stressrelated proteins, only one of $K$. olearia's three cold shock proteins (Kole_0109) showed significantly higher expression at $40{ }^{\circ} \mathrm{C}$, but its up-regulation was merely moderate when compared to its expression levels at $30{ }^{\circ} \mathrm{C}$ (Table S5; Fig. S2B). Taken together, the observed expression patterns of known cold stress-related genes are consistent with the cells being in a non-stressed state at $40{ }^{\circ} \mathrm{C}$.

\section{$K$. olearia is in cold stress at $30{ }^{\circ} \mathrm{C}$}

Among the three most highly expressed up-regulated genes at $30{ }^{\circ} \mathrm{C}$ are two Csp-encoding genes (Kole_0109 and Kole_2064, Table S5; Fig. S2C), suggesting that the cells were in a cold-stressed state during growth at $30^{\circ} \mathrm{C}$. In support of this, there was also significant up-regulation of other genes previously linked to bacterial cold response (e.g., Alreshidi et al. 2015; Barria et al. 2013), including a DEAD/ DEAH-box RNA helicase (Kole_0922), rbfA (Kole_2103), nusA (Kole_1529) and ribosomal proteins L10 (Kole_1840) and L7/L12 (Kole_1839). Genes encoding several additional ribosomal proteins and ribosomal RNA (rRNA) methyltransferases, $r m l H$ (Kole_1718) and $r m l L$ (Kole_0897), were also up-regulated (Fig. 3; Table S5).

To detect a decrease in environmental temperature and elicit an appropriate regulatory response, some bacteria have evolved two-component cold sensors (de Mendoza 2014). These signal transduction systems consist of a sensor, a membrane-integrated protein with a kinase domain that detects changes in the fluidity of the cell membrane, and the cytoplasmic response regulator, a protein that induces expression of cold-responsive genes. In $K$. olearia, a histidine kinase with two predicted transmembrane domains (Kole_1017) and two response regulators (Kole_1015 and Kole_1016) showed a steady increase in expression as temperatures decreased from $65^{\circ} \mathrm{C}$, but no significant change in expression at $77{ }^{\circ} \mathrm{C}$ (Table S5), leading us to hypothesize that these genes encode a cold-sensing two-component system.

At $30{ }^{\circ} \mathrm{C}$, and to a lesser extent at $40{ }^{\circ} \mathrm{C}$, we also observed an over-representation of highly expressed genes involved in amino acid metabolism (COG category E). Specifically, several genes in the arginine (Kole_0092-Kole_0097) and lysine (Kole_0104-Kole_0107, $30{ }^{\circ} \mathrm{C}$ only) biosynthesis pathways were up-regulated, suggesting the potential for accumulation of peptides and amino acids (or their intermediates) at lower temperatures. Interestingly, while the cells may accumulate peptides at $30^{\circ} \mathrm{C}$, at $40{ }^{\circ} \mathrm{C}$ there was increased expression of an oligo-peptidase (Kole_1190) and genes involved in lysine degradation (Kole_0958, Kole_0963-Kole_0966). Such distinguishably different metabolic responses to moderately low $\left(40{ }^{\circ} \mathrm{C}\right)$ and low $\left(30^{\circ} \mathrm{C}\right)$ temperatures suggest a fine-tuned temperature-dependent peptide turnover.

\section{K. olearia is in heat stress at $77^{\circ} \mathrm{C}$}

Since $77{ }^{\circ} \mathrm{C}$ is near the upper limit for $K$. olearia growth under our laboratory conditions, we hypothesize that the observed differences in expression profiles at 65 and $77{ }^{\circ} \mathrm{C}$ would reflect a cell-wide heat stress response. Of the 169 significantly differentially expressed genes, 119 showed increased expression at $77{ }^{\circ} \mathrm{C}$ (Table S5; Fig. S2D). Among the most highly expressed genes were those encoding the structural RNAs ffs (Kole_R0010), ssrA (Kole_R0006), and rnpB (Kole_R0049) (Fig. 3), suggesting an increased rate of RNA turnover at supraoptimal temperature. Moreover, genes involved in carbohydrate and energy metabolism (COG C and $\mathrm{G}$ categories) were over-represented and up-regulated at $77^{\circ} \mathrm{C}$ (Fig. 4; Table S5). However, only two of the known heat shock response genes (Pysz et al. 2004), the extreme heat stress sigma factor-24 (rpoE, Kole_2150) and the heat shock protease (Kole_1599), were up-regulated, and 41 
of 119 genes (34\%) are annotated as "hypothetical proteins", indicating that adaptation to growth at sustained high temperature remains largely uncharacterized. Putative functions could be inferred for some of the encoded proteins of these 41 genes of unknown function. Seventeen of the 41 proteins have predicted signal peptides, suggesting that they may be secreted, and four have two or more predicted transmembrane regions, suggesting that they are membrane associated. Kole_0652 carries a PrcB-domain, which interacts with and stabilizes PrtP protease (Godovikova et al. 2010). Kole_1314 (and its paralog Kole_1297) contains an AbiEii-toxin domain, and may be part of a toxin-antitoxin system. Furthermore, the 41 genes could be grouped into 34 transcriptional units, each containing at most three of these genes (Table S2) and scattered across the $K$. olearia genome. Two of the genes, Kole_1430 and Kole_1431, are co-transcribed with genes from a two-component system (Kole_1428 and Kole_1429), suggesting that they may be involved in environmental sensing or signaling. Three other cotranscribed genes (Kole_1266, Kole_1267, Kole_1270) are found in a cluster containing CRISPR-genes, and two of them (Kole_1266 and Kole_1270) contain RAMPdomains, suggesting CRISPR-related function (Makarova et al. 2011). The majority of the 41 genes of unknown function have homologs in genomes of other Kosmotoga spp. $(N=38)$, Mesotoga spp. $(N=23)$, and other Thermotogae $(N=26)$.

\section{Global regulators of temperature response}

The transcriptional changes seen at the sub- and supraoptimal temperatures are likely to be controlled by one or a few global regulators (Balleza et al. 2009), such as some temperature sensors (de Mendoza 2014) and sigma factors needed for transcription initiation (Buck et al. 2000). The two-component cold sensor up-regulated at low temperatures (Kole_1015-Kole_1017) may represent one such global regulator. Two different sigma factors, Kole_2150 and Kole_1408, were significantly up-regulated at $77^{\circ} \mathrm{C}$ and at 30 and $40^{\circ} \mathrm{C}$, respectively (Table S5), hinting at existence of temperature-specific sigma factors. Kole_2150 belongs to the sigma-24 ECF subfamily, which is activated in response to environmental stress (Balleza et al. 2009). Kole_1408 belongs to the sigma-54 family, which is involved in enhancer-dependent transcription (Buck et al. 2000), introducing the possibility that this sigma factor may be a target of the two-component cold sensor. In general, at both 30 and $77^{\circ} \mathrm{C}$ the differentially expressed genes were enriched in genes involved in transcriptional regulation (COG category K) (Fig. 4), leaving a possibility of additional global regulators.
Conservation of $K$. olearia's temperature-responsive genes within the Kosmotoga genus

All genes that are required for adaptation and response of $K$. olearia strain TBF 19.5.1 to a wide range of growth temperatures are expected to be present in other $K$. olearia isolates, whereas some may be absent from Kosmotoga species that have a narrower spectrum of growth temperature. Therefore, we contrasted the K. olearia genome to the genomes of Kosmotoga sp. DU53 and Kosmotoga arenicorallina (Pollo et al. 2016). When compared to K. olearia, Kosmotoga sp. DU53 has a similar growth temperature range $\left(25-79^{\circ} \mathrm{C}\right.$, Table S7) and $>99 \%$ average nucleotide identity (ANI), while $K$. arenicorallina exhibits a narrower growth temperature range $\left(35-70{ }^{\circ} \mathrm{C}\right.$, Table S7) and has only $84 \%$ ANI.

Indeed, the Kosmotoga sp. DU53 genome lacks only 10 of the $573 \mathrm{~K}$. olearia putative temperature-responsive genes (BLASTP and TBLASTN searches, $E$ value $<10^{-3}$, Table S5). All 10 genes were expressed in $K$. olearia at relatively low levels, suggesting that they are unlikely to be essential for high- or low-temperature growth. On the other hand, the $K$. arenicorallina genome does not have detectable homologs of 103 of the $573 \mathrm{~K}$. olearia's putative temperature-responsive genes (BLASTP and TBLASTN searches, $E$ value $<10^{-3}$; Table S5). The list of absent genes includes several of the arginine and lysine biosynthesis genes that are up-regulated in $\mathrm{K}$. olearia during growth at $30^{\circ} \mathrm{C}$, and seven of the genes of unknown function up-regulated at $77^{\circ} \mathrm{C}$. Therefore, we hypothesize that a subset of these 103 genes may play a role in extending the growth range of $K$. olearia to $\leq 35$ and $\geq 70{ }^{\circ} \mathrm{C}$.

\section{Many key temperature-responsive genes are laterally acquired}

Obtaining "pre-adapted" genes from other genomes is one way prokaryotes adjust to new environmental conditions (Boucher et al. 2003). Using HGTector (Zhu et al. 2014) we predicted that 354 of $K$. olearia's 2118 proteincoding genes have been acquired laterally by $K$. olearia or the Kosmotogales (i.e., Kosmotoga and Mesotoga genera), presumably representing LGT events occurring after the divergence of Kosmotogales from other Thermotogae (Table S8). Eighty-eight of the 354 genes were temperature responsive (Table S5; Fig. S5A, S5B), including several above-discussed highly expressed genes (Table 1), and 37 of the 88 genes are shared with Mesotoga (Table S5). Notably, $76 \%$ of these 37 genes are up-regulated at $30{ }^{\circ} \mathrm{C}$ (Fig. S5C), suggesting that their acquisition may have been important in adaptation to low-temperature growth. Among these are the earlier mentioned rRNA methyltransferase genes (Kole_1718 and Kole_0897). The fatty acid synthesis genes (Kole_0969-Kole_0973) that are up-regulated 
Table 1 Gene expression in selected laterally acquired temperature-responsive genes

\begin{tabular}{|c|c|c|c|c|c|c|}
\hline \multirow[t]{2}{*}{ Locus tag } & \multirow[t]{2}{*}{ Functional annotation } & \multicolumn{4}{|c|}{ RPKM values } & \multirow[t]{2}{*}{ Identified by } \\
\hline & & $30^{\circ} \mathrm{C}^{\mathrm{a}}$ & $40^{\circ} \mathrm{C}$ & $65^{\circ} \mathrm{C}$ & $77^{\circ} \mathrm{C}$ & \\
\hline Kole_0109 & Cold shock protein & 5602 & 892 & 222 & 119 & Phylogenetic analysis ${ }^{\mathrm{a}}$ \\
\hline Kole_0110 & Histidine kinase & 175 & 333 & 144 & 312 & Phylogenetic analysis \\
\hline Kole_0111 & Response regulator & 166 & 204 & 173 & 446 & HGTector \\
\hline Kole_0505 & Glycerol dehydrogenase & 721 & 2668 & 752 & 1242 & HGTector \\
\hline Kole_0506 & Hypothetical protein & 559 & 2037 & 461 & 783 & Phylogenetic analysis \\
\hline Kole_0507 & Hypothetical protein & 555 & 2193 & 521 & 809 & HGTector \\
\hline Kole_0508 & Poly (3-hydroxybutyrate) depolymerase-like protein & 212 & 423 & 200 & 314 & HGTector \\
\hline Kole_0897 & Ribosomal RNA methyltransferase, rmlL & 503 & 498 & 228 & 232 & HGTector \\
\hline Kole_0922 & DEAD/DEAH box helicase & 755 & 288 & 89 & 102 & HGTector \\
\hline Kole_0969 & 3-oxoacyl-ACP synthase III, FabH & 2386 & 3063 & 939 & 1424 & HGTector \\
\hline Kole_0970 & enoyl-ACP reductase II, fabK & 2226 & 3243 & 1486 & 1641 & HGTector $^{\mathrm{a}}$ \\
\hline Kole_0971 & malonyl CoA-acyl carrier protein transacylase, fabD & 2304 & 4211 & 2303 & 2647 & HGTector \\
\hline Kole_0972 & acyl carrier protein & 6531 & 12601 & 4850 & 4241 & HGTector \\
\hline Kole_0973 & 3-oxoacyl-ACP synthase II, fabF & 4815 & 9257 & 4753 & 4498 & HGTector \\
\hline Kole_1015 & Response regulator & 1289 & 515 & 95 & 130 & HGTector \\
\hline Kole_1016 & Response regulator & 783 & 280 & 54 & 72 & HGTector \\
\hline Kole_1017 & Histidine kinase & 697 & 275 & 59 & 90 & Phylogenetic analysis \\
\hline Kole_1718 & Ribosomal RNA methyltransferase, $\mathrm{rmlH}$ & 531 & 332 & 211 & 203 & HGTector \\
\hline Kole_1745 & PPIase FKBP-type & 2783 & 2382 & 1541 & 430 & HGTector \\
\hline
\end{tabular}

At each temperature, the listed RPKM values represent the average expression levels across replicates. Values that are significantly different from $65{ }^{\circ} \mathrm{C}$ are shown in bold font. None of the temperature-responsive expression patterns shows significant effect of growth rate and, where tested (i.e., $|R|>0.7$ ), the growth-rate-only model was rejected

${ }^{a}$ Phylogenetic tree is shown in Fig. S6

at $40{ }^{\circ} \mathrm{C}$, as well as their Kosmotogales homologs, form a distantly related sister clade to other Thermotogae lineages (Fig. S6A), implying that these genes may have been acquired from an un-sampled lineage. Similarly, the Cspencoding gene highly expressed at $30{ }^{\circ} \mathrm{C}$ (Kole_0109) is placed outside of the Thermotogae clade (Fig. S6B).

Notably, some putative lateral gene acquisitions by $K$. olearia do not have homologs in Mesotoga. These include genes encoding the predicted cold temperature sensor (Kole_1015-Kole_1017), one of the PPIase genes (Kole_1745), as well as the canonical cold response enzyme DEAD/DEAH box RNA helicase (Kole_0922). Absence of these genes in Mesotoga suggests their potential importance for $K$. olearia's ability to grow over a wide temperature range.

\section{Discussion}

\section{How can $K$. olearia grow at such a wide range of temperature?}

Examination of $K$. olearia's transcriptional response to sustained exposure to a non-optimal temperature revealed both high expression of core metabolic genes and differential expression of hundreds of other genes, with selected features highlighted in Fig. 5. At each tested temperature, core metabolism genes for pyruvate utilization show high relative expression, which strongly suggests that $K$. olearia uses the same proteins for its core energy metabolism and that these proteins can function across its wide growth temperature range. In contrast, genes involved in regulatory functions showed significant changes in expression at all temperatures, particularly at 30 and $77{ }^{\circ} \mathrm{C}$ (COG category $\mathrm{K}$ and $\mathrm{T}$ in Fig. 4), suggesting that regulating gene expression is important in response to a temperature shift. Among these genes, we identified putative global temperature regulators: the two-component cold sensor and temperature-specific sigma factors.

Close to $K$. olearia's growth temperature maximum of $77{ }^{\circ} \mathrm{C}$, carbohydrate and energy metabolism genes (COG categories $\mathrm{C}$ and $\mathrm{G}$ ) were up-regulated (Fig. 4). It is unclear, however, if the underlying cause is the increased turnover of enzymes at elevated temperatures, a demand for more enzymes due to increased carbohydrate catabolism, or a combination of these factors. Increased carbohydrate metabolism in response to prolonged growth at supra-optimal temperature has been observed previously in T. maritima (Wang 


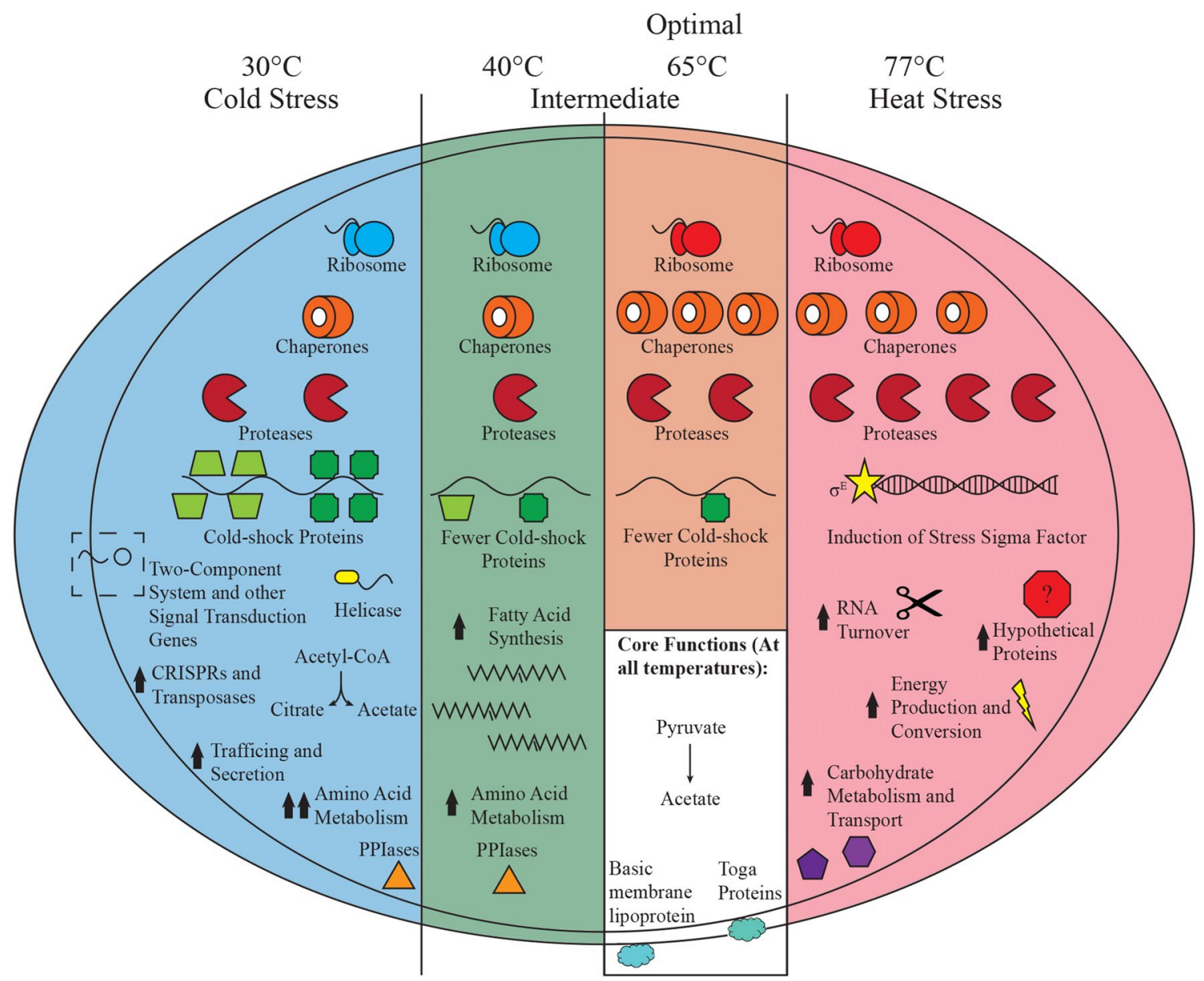

Fig. 5 Schematic of $K$. olearia's major temperature-induced transcriptional responses. Major responses outlined in the text occurring in the three states observed are shown. The number of chaperone, protease, and cold-shock symbols reflects their relative expression at each temperature. Chaperones include groEL (Kole_1627), groES (Kole_1626), and dnaK (Kole_0886). Proteases refer to protease Do (Kole_1599) and protease La (Kole_0536). Cold-shock genes consist of Kole_2064 (dark green squares) and Kole_0109 (green trapezoids). The different colored ribosomes represent changes in ribosomal protein composition at sub-optimal temperatures (see text

et al. 2012) and, therefore, may be a common adaptation to high-temperature growth in the Thermotogae. As observed for $K$. olearia, the prolonged supra-optimal temperature growth of T. maritima also did not involve up-regulation of typical heat-shock response proteins (Wang et al. 2012). This highlights the difference between cellular response to an immediate heat-shock and to prolonged growth at supraoptimal temperature (Balleza et al. 2009), and in general justifies classifying the cellular response to temperature into these two distinct categories.

At the moderately sub-optimal growth temperature of $40{ }^{\circ} \mathrm{C}, \mathrm{K}$. olearia cells face physiological challenges of proper protein folding (Godin-Roulling et al. 2015), and of maintenance of a functional cell membrane (de Mendoza for "Discussion"). The putative two-component regulatory system (Kole_1015-1017) that had a dramatic increase in expression under cold stress is shown. Prominent changes in functional categories (COGs) for each temperature condition are also shown. Arrows indicate relative gene expression when compared to growth at optimal temperature. Core functions occurring at all temperatures are shown in the white box. Basic membrane lipoprotein and the major toga anchor protein refer to Kole_1554 and Kole_1500, respectively. See Fig. 2 for genes involved in pyruvate metabolism

2014). Our observation that at $40{ }^{\circ} \mathrm{C}$, despite the lower growth rate, lipid metabolism genes were among the most highly expressed genes suggests that changes to the cell membrane composition are one of the most important adaptations for survival of $K$. olearia at lower temperatures. Proper protein folding may require enzymatic assistance (Godin-Roulling et al. 2015), which may be achieved via $K$. olearia's three PPIases. The significant up-regulation of the PPIase genes at $40{ }^{\circ} \mathrm{C}$ suggests that they are particularly important at moderately low temperatures where the cells are still relatively active. However, the overall lack of induction of typical stress-related genes at $40{ }^{\circ} \mathrm{C}$, especially when compared to 30 and $77^{\circ} \mathrm{C}$, suggests that $40{ }^{\circ} \mathrm{C}$ is within the "Goldilocks" temperature range for $\mathrm{K}$. olearia. 
At $30^{\circ} \mathrm{C}$, K. olearia is clearly under cold stress (Fig. 5), as evidenced by expression of genes known to be implicated in cold response. One of the strategies for maintenance of proper cellular function at non-optimal temperatures (Pollo et al. 2015) is accumulation of compatible solutes. Specifically, re-modeling of amino acid metabolism and the possible accumulation of amino acids as compatible solutes at low temperatures have been observed in bacteria (e.g., Dahlsten et al. 2014; Ghobakhlou et al. 2015). The up-regulation of many genes involved in amino acid metabolism suggests that $K$. olearia may also accumulate amino acids or their intermediates for this purpose, especially at $30^{\circ} \mathrm{C}$. At $30^{\circ} \mathrm{C}$, there was also significant up-regulation of a citrate synthase gene (Kole_1230), suggesting that K. olearia cells may accumulate citrate, as was observed in Staphylococcus aureus during prolonged cold stress (Alreshidi et al. 2015). Alternatively, citrate synthase, together with isocitrate dehydrogenase (Kole_1227), may be involved in converting pyruvate or acetyl-CoA to 2-oxoglutarate, a precursor for several amino acids including arginine, which has been suggested to accumulate in for instance Clostridium (Dahlsten et al. 2014). Interestingly, the genome of strictly mesophilic $M$. prima encodes more genes involved in amino acid metabolism than the genomes of $K$. olearia and other thermophilic Thermotogae (Zhaxybayeva et al. 2012). This supports the notion that the shift towards more amino acid metabolism in $K$. olearia may be an adaptation to low-temperature growth and suggests that the mesophilic Mesotoga have taken this a step further by also acquiring more amino acid metabolism genes. Moreover, amino acid metabolism genes are among the most numerous bacterial genes laterally acquired by mesophilic archaea, which is hypothesized to reflect archaeal adaptation to low-temperature growth (López-García et al. 2015).

Ribosomes also need to be fine-tuned (i.e., to adjust the stoichiometric proportions of accessory proteins) to function properly at low temperature (Barria et al. 2013). Consistently, we observed a change in expression of several genes encoding ribosomal proteins. The most dramatic differential expression, however, was observed for a ribosomal protein gene not yet connected to cold response (L34; Kole_0258, Fig. 3; Table S5). L34, a bacteria-specific ribosomal protein hypothesized to be a relatively recent addition to the evolving ribosome (Fox 2010), is required for proper ribosome formation (Akanuma et al. 2014). A Bacillus subtilis mutant lacking the L34 gene showed particularly slow growth at low temperature (Akanuma et al. 2012), suggesting a role for L34 in this condition. We also observed significant increased expression of rRNA methyltransferases, and methylation of rRNAs has been associated with responses to environmental stress, including temperature (Baldridge and Contreras 2014). Therefore, we hypothesize that $K$. olearia modifies its ribosome by changing stoichiometry of the ribosome components and by methylating rRNA. Time required for such ribosomal adjustments could also explain the longer lag phase following temperature shifts (Fig. S1).

Expansion of cold-responsive gene families may represent a common strategy for low-temperature adaptation, as has been noted in many bacteria, especially in psychrophiles (e.g., Piette et al. 2010). K. olearia exhibits the same trend. For instance, when compared to other Thermotogae, all three analyzed Kosmotoga genomes harbored more copies of Csp-encoding genes (Table S9). The observed gene family expansions, however, might be important not necessarily for low-temperature growth alone, but instead for growth over a wide temperature interval. Mesotoga functions with only a single $c s p$ gene, demonstrating that having more copies of this gene is not required for low-temperature growth. Having several versions of a gene could make differential regulation under different growth temperatures easier. For example, extra homologs (Kole_0111 and Kole_0110) of the earlier-discussed putative cold sensor system do not show coordinated temperature responses: Kole_0110 is up-regulated at $40{ }^{\circ} \mathrm{C}$, while Kole_0111 is up-regulated at $77{ }^{\circ} \mathrm{C}$ (Table 1). Therefore, these additional homologs may encode sensors tuned to different temperatures.

\section{Evolutionary mechanisms that drive adaptive changes in Kosmotogales genomes}

Gene family expansions can be achieved via within-lineage gene duplication or through LGT, and a combination of these mechanisms appears to be at work in $K$. olearia. For example, even though several Thermotogae genomes contain as many copies of PPIase genes as do Kosmotoga genomes (Table S9), phylogenetic analysis suggests that in the Kosmotogales this gene family has only recently been expanded by both LGT (the FKBP-type, Table 1) and duplication (the PpiC-type, Fig. S6C). Similar conclusions can be made from the phylogenetic analyses of $c s p$ genes (Fig. S6B).

LGT appears to be a significant factor in evolution of low-temperature growth in Kosmotogales. In $K$. olearia although the proportion of transferred genes among the temperature-responsive genes is similar to what is observed in the genome (Fig. S5), many of the genes identified here as key for low-temperature growth have been acquired by LGT. For instance, the fatty acid synthesis genes with high expression at $40{ }^{\circ} \mathrm{C}$ were acquired by LGT into the Kosmotogales and are likely important for low-temperature growth in both Mesotoga and Kosmotoga. Other key LGT genes including the DEAD/DEAH box RNA helicase, the temperature sensor, and the low-temperature-induced csp genes are only found in Kosmotoga spp. and may, therefore, be more important for its wide temperature growth (Table 1). The predicted acquisition of fatty acid synthesis and csp genes by (now mesophilic) archaea (López-García et al. 
2015) additionally argues for the importance of these genes in adaptation to low-temperature growth.

Despite the importance of expanded gene families in low-temperature adaptation, the role of mutation and consequent natural selection on specific genes in response to changing environmental conditions should not be neglected. For example, typical cold response genes $r b f A$ (Kole_2103) and nusA (Kole_1529) were not laterally acquired, but nevertheless show high expression only at $30^{\circ} \mathrm{C}$. Deciphering adaptive changes that occurred in such genes compared to thermophilic homologs may elucidate molecular mechanisms of low-temperature adaptation.

\section{Why maintain the capacity for growth over such a wide temperature range?}

Most bacteria are under selection to eradicate extraneous DNA (and genes) from their genomes (Graur 2016), and among free-living bacteria Thermotogae in general have very compact genomes. Kosmotogales, however, have notably larger genomes than other thermophilic Thermotogae (Pollo et al. 2015; Zhaxybayeva et al. 2012), raising the possibility that expanded genomes are advantageous in $K$. olearia's habitat. As discussed above, many of the genes in $K$. olearia, such as the cold-sensor system, were expressed only at specific sub- or supra-optimal temperatures, and do not seem to be important for growth at other temperatures (Table 1, Table S5). The regulated response to low temperatures and the preservation of the laterally acquired genes specifically expressed at 40 and $30{ }^{\circ} \mathrm{C}$ suggest that $K$. olearia encounters environments with very different temperatures frequently enough to maintain these genes in its genome. Such environments may include oil reservoirs located at different depths, as well as marine sediments influenced by the mixing of cold deep-sea water and hydrothermal fluids (Sievert and Vetriani 2012). Perhaps, K. olearia migrates between such locations via subsurface fluids and, as a result, may have been selected to become a temperature generalist. Indeed, the environmental conditions of the subsurface environments and marine hydrothermal vents from which Kosmotoga spp. have been detected and/or isolated vary substantially (DiPippo et al. 2009; Nunoura et al. 2010; L'Haridon et al. 2014; Vigneron et al. 2017; Duncan et al. 2009, 2014; Gittel et al. 2009; Kotlar et al. 2011; Pollo et al. 2016; Oko et al. 2017; Bordenave et al. 2013; Nesbø et al. 2010). Moreover, Kosmotoga sp. DU53, which is most similar to $K$. olearia, was isolated from an oil reservoir with an in situ temperature of $\sim 50{ }^{\circ} \mathrm{C}$, while $K$. arenicorallina was obtained from hydrothermal sediments with a temperature of $\sim 40{ }^{\circ} \mathrm{C}$ (Nunoura et al. 2010). Notably, K. olearia was also identified as a major constituent of a metagenome from a deep subsurface oil reservoir with in situ temperature of $85^{\circ} \mathrm{C}$ and pressure of $25 \mathrm{MPa}$ (Kotlar et al. 2011). While the reservoir temperature is higher than the maximum $K$. olearia growth temperature reported here, elevated pressure could extend $K$. olearia's temperature maximum, as has been demonstrated for some archaea (e.g., Takai et al. 2008). Therefore, $K$. olearia's growth temperature range under natural conditions may be even broader than $20-79{ }^{\circ} \mathrm{C}$.

\section{Conclusions}

The present study demonstrates that even bacteria with relatively small genomes can use transcriptional changes to respond effectively to large changes in temperature (Fig. 5). We showed that $K$. olearia's response to sustained exposure to a non-optimal temperature includes up-regulation of hundreds of genes. Several key genes with known temperaturerelated functions apparently have been acquired laterally, suggesting that LGT is an evolutionarily successful strategy for expansion of temperature tolerance. However, gene duplication and subsequent neo-functionalization of the paralogs likely also play an important adaptive role.

The ability of $K$. olearia to inhabit both high- and lowtemperature environments suggests that members of this lineage encounter environments with large temperature fluctuations and/or migrate across ecological niches within the deep biosphere (e.g., between deep and shallow subsurface oil reservoirs). Therefore, the subsurface environments, as well as their microbial populations, might be viewed as a connected archipelago instead of isolated islands. As a corollary, we speculate that $K$. olearia-like ecological generalists could also facilitate LGT among seemingly isolated deep biosphere microbial communities adapted to a narrower ecological niche. For example, we have previously demonstrated high levels of gene flow among hyperthermophilic Thermotoga populations in subsurface oil reservoirs and marine hydrothermal vents (Nesbø et al. 2015), environments that are separated by non-thermophilic surroundings but are hydrologically linked. The mechanism of such gene flow is not yet known, but $K$. olearia-like Thermotogae capable of growing both in subsurface oil reservoirs and adjacent marine sediments could serve as mediators of gene exchange.

Although some of the identified 573 temperatureresponsive genes are already known to be expressed in bacteria and archaea grown at high or low temperatures, most of the up-regulated genes have not previously been implicated in temperature response and are in need of better functional and biochemical characterization. Moreover, the majority of the K. olearia genes responsive to elevated temperature encode proteins of unknown functions. Versatile proteins that work across a broad range of temperatures also warrant further biochemical and evolutionary 
analyses, as understanding of their enzymatic flexibility can aid the design of commercially important thermostable proteins.

\section{Materials and methods}

\section{Bacterial culturing}

K. olearia TBF 19.5.1 [DSM 21960(T), ATCC BAA1733(T), Genbank accession number NC_012785] was grown at different temperatures $\left(30,40,65\right.$, and $\left.77^{\circ} \mathrm{C}\right)$, but otherwise optimal conditions, in Kosmotoga medium (KTM) using pyruvate as growth substrate as described in (DiPippo et al. 2009). Cultures used as inocula were stored at $4{ }^{\circ} \mathrm{C}$, except those used for experiments at $\geq 77^{\circ} \mathrm{C}$. Actively growing cultures at temperatures $\geq 77^{\circ} \mathrm{C}$ had to be used directly as inoculum because the cultures would not grow from inocula stored at either $4{ }^{\circ} \mathrm{C}$ or room temperature $\left(\sim 22{ }^{\circ} \mathrm{C}\right)$. Replicate cultures received the same volume of inoculum; however, variable inoculum volume was used at different temperatures (Table S1), as larger inoculum volumes were required to achieve growth at the non-optimal temperature treatments.

\section{Measurement of $K$. olearia growth at different temperatures}

Growth curves were constructed from optical density measurements at $600 \mathrm{~nm}\left(\mathrm{OD}_{600}\right)$ using an Ultrospec 3100 pro. For cultures grown at $40,65,77$, and $78{ }^{\circ} \mathrm{C}$ two sets of triplicate bottles, inoculated from the same inoculum $12 \mathrm{~h}$ apart, were monitored for a $12 \mathrm{~h}$ period per day to generate the growth curves. The cultures for isothermic growth at $40,65,77$, and $78{ }^{\circ} \mathrm{C}$ were monitored hourly, while the cultures for shifted growth at these temperatures were monitored every $1-5 \mathrm{~h}$. At $30{ }^{\circ} \mathrm{C}$, one set of triplicate bottles was monitored once daily. Isothermic growth curves were calculated from six replicates, except for the curves for 30 and $77{ }^{\circ} \mathrm{C}$ that had three and 12 replicates, respectively. All shifted growth curves consisted of six replicate cultures, except for 40 and $30{ }^{\circ} \mathrm{C}$ which had four and three replicates, respectively. To determine growth rates (Fig. 1), for each culture the $\operatorname{lnOD}_{600}$ was plotted against growth time and the curve was fitted with a linear trend line. The growth rate was defined as the slope at the log phase. To determine the time span of each growth phase (Fig. S1), full composite growth curves were constructed using pooled replicate data. For each curve, $\mathrm{OD}_{600}$ for all replicates was plotted against growth time and a polynomial regression trend line was fitted.

\section{Cultivation of Kosmotoga sp. DU53 and $K$. arenicorallina, and confirmation of their growth temperature ranges}

Kosmotoga sp. DU53 was grown in KTM as described above for $K$. olearia. $K$. arenicorallina was also grown in KTM; however, maltose was used as substrate $(2.5$ and $0.5 \mathrm{~mL}$ $10 \%$ maltose was added to serum bottles and Hungate tubes, respectively). One milliliter of culture was used as inoculum for all cultures (bottles and tubes). The temperature range of each strain was assessed by examination of culture turbidity as a proxy for growth. Starting from cultures grown at optimal growth temperature $\left(\sim 65^{\circ} \mathrm{C}\right.$ for Kosmotoga sp. DU53 and $60^{\circ} \mathrm{C}$ for $K$. arenicorallina), new cultures were shifted in $\leq 10^{\circ} \mathrm{C}$ increments. If growth was observed after a shift, then that culture was used to initiate a new culture. The shifting procedure was terminated when growth was no longer evident at a given temperature.

\section{RNA isolation and processing}

Cultures used for RNA extraction were inoculated from cultures that had been grown under the same temperature conditions for at least three transfers. The time at which a culture was expected to be in a desired growth phase was determined from the composite growth curves (Fig. S1), and was used as a cell harvesting time (listed in Table S1). This procedure avoided exposure of the cultures to the lower ambient temperatures in the laboratory during subsampling. For the $30{ }^{\circ} \mathrm{C}$ cultures, $\mathrm{OD}_{600}$ was additionally measured $24 \mathrm{~h}$ before harvesting to ensure the culture was in mid-log phase. To stabilize the transcripts and to avoid any transcriptional response to the change in temperature, an equal volume of "stop solution" (10\% phenol in ethanol) was added to the sealed cultures via syringe immediately upon removal from the incubator. For each temperature treatment, RNA was extracted in mid-log to late-log phase, using the Zymo Research Fungal/Bacterial RNA MiniPrep Kit (Cedarlane Laboratories, Ltd.; Burlington, Ontario) and following the manufacturer's protocols (Table S1).

Following recommendations in (Haas et al. 2012), we aimed to sequence $\sim 3$ million non-ribosomal-RNA reads per sample. Ribosomal RNA (rRNA) depletion was performed on all samples using the Ribo-Zero rRNA Removal Kit (Gram-Positive Bacteria) Magnetic Kit (MRZGP126, Epicentre). On average, two aliquots containing $5 \mu \mathrm{g}$ total RNA (the maximum amount allowed by the Ribo-Zero kit) needed to be rRNA-depleted and then pooled to generate sufficient input RNA (200-500 ng for Ion Torrent PGM and 10-400 ng for Illumina MiSeq), although some samples required as many as five rRNA depletions. Quality and quantity of the total RNA, as well as efficiency of rRNA depletion, were assessed on an Agilent 2100 Bioanalyzer RNA 
Nano chip or RNA Pico chip following the manufacturer's instructions for "Prokaryote Total RNA". RNA successfully depleted of rRNA was used to construct RNA-Seq libraries following the manufacturer's instructions, and sequenced on either an Ion Torrent PGM (RNA-Seq kit V2; transcriptomes are labeled with an "IT" suffix) or an Illumina MiSeq (TruSeq RNASeq v2 $2 \times 100 \mathrm{bp}$ ). The platform and RNA extraction technique used for each transcriptome are summarized in Table S1. The transcriptomes are available in the Sequence Read Archive (http://www.ncbi.nlm.nih.gov/sra) under the accession number SRP075860.

\section{RNA-Seq analysis}

For each transcriptome, sequenced reads were analyzed using the "RNA-Seq" function in CLC Genomics Workbench version 7.0.4 (https://www.qiagenbioinformatics. $\mathrm{com} /$ ). Briefly, reads were first trimmed allowing no more than 2 ambiguous nucleotides and a maximum base-calling error probability of 0.05 . To remove sequences that matched remaining rRNA transcripts, the trimmed reads were subjected to a relaxed mapping protocol: only rRNA genes were used as a "reference genome", and reads were mapped only to the reference sequences if at least half of the alignment (length fraction $=0.5$ ) had at least $50 \%$ identity to the reference (similarity fraction $=0.5$ ); all other parameters were set to default (maximum number of hits for a read $=10$, map to both strands, mismatch cost $=2$, insertion cost $=3$, deletion $\operatorname{cost}=3$, auto-detect paired distances). The mapped reads were designated as rRNA and were removed from further analysis.

The remaining reads were subjected to an RNA-Seq protocol with strict mapping parameters: at least $95 \%$ of the alignment had to have at least $95 \%$ identity (i.e., similarity fraction $=0.95$; length fraction $=0.95$ ) to the reference (the $K$. olearia TBF 19.5.1 annotated genome), mapping to intergenic regions was allowed, and all other default settings as described above. Unmapped reads were discarded. Expression levels for every gene were estimated using "Reads Per Kilobase of transcript per Million mapped reads" (RPKM) values.

RPKM values for all genes are listed in Table S4. Differentially expressed genes were identified by doing pairwise comparisons of Illumina transcriptomes of the isothermically grown cultures at 30,40 , and $77{ }^{\circ} \mathrm{C}$ to the cultures grown at the optimal temperature of $65^{\circ} \mathrm{C}$. The analyses used the "Empirical Analysis of DGE" function in CLC Genomics Workbench, which employs the "Exact Test" for two-group comparisons (Robinson and Smyth 2008). A gene was considered differentially expressed in a pairwise comparison if it had (i) $>20$ reads in at least one of the two transcriptomes, (ii) a statistically significant difference in the RPKM values (corrected for multiple testing using false discovery rate $<0.05$ ), and (iii) a difference in RPKM values at least twofold in magnitude. PCA and biplot visualization were performed using R packages ade4 and bpca, respectively (Dray et al. 2007; Faria et al. 2013). Each gene was assigned to a Clusters of Orthologous Groups (COG; Galperin et al. 2015) functional category using the Integrated Microbial Genomes (IMG) portal (Markowitz et al. 2014). Genes assigned to more than one COG category were counted in all assigned categories. Signal peptides and membrane domains were identified in Geneious v.9.

Batch culture cannot selectively discern gene expression that is exclusively influenced by temperature from expression that is solely growth rate dependent. In theory, continuous culture conducted at a single growth rate could afford such discrimination. However, given the extremely slow growth of $K$. olearia near its temperature maxima and minima (Fig. 1), it was not feasible to use anaerobic bioreactors to cultivate cells at this marginal growth rate across the temperature range. Hence, in order to assess how differences in growth rates influence the expression patterns, we examined correlations of the expression pattern of the putative temperature-responsive genes with growth rates calculated at each temperature. Pearson correlation of expression values and growth rates was calculated in Microsoft Excel. ANCOVA, linear regression, and likelihood ratio tests were carried out in R. The "growth rate only" model was the linear regression (expression $=$ growth rate). In the ANCOVA model, growth rates were set as the quantitative variable and temperature as qualitative variable (expression $=$ growth rate + temperature). The growth rates used were 0.006 for $30{ }^{\circ} \mathrm{C}, 0.087$ for $40{ }^{\circ} \mathrm{C}, 0.274$ for $65^{\circ} \mathrm{C}$ and 0.107 for $77^{\circ} \mathrm{C}$ (see Fig. 1). When comparing the most significant temperature coefficient to the growth rate coefficient, the latter was scaled by the average growth rate $(0.115)$. The growth rate effect was defined as being greater than the temperature rate effect if $\mid$ temperature/(growth rate $\times 0.115) \mid<1$.

\section{Identification of genes involved in growth on pyruvate}

$K$. olearia genes predicted to be involved in pathways for pyruvate conversion to acetate, $\mathrm{CO}_{2}, \mathrm{H}_{2}$ and ATP were retrieved from the KEGG (Kanehisa et al. 2014) and BioCyc (Caspi et al. 2014) databases. Genes encoding hydrogenases were taken from (Schut et al. 2012), and genes encoding the F-type ATPase subunits were identified using IMG (Markowitz et al. 2014).

\section{Fatty acids analysis}

Total lipids were extracted from $K$. olearia grown at $40{ }^{\circ} \mathrm{C}$ to early stationary phase and $65^{\circ} \mathrm{C}$ to mid-log, early stationary, late stationary and death phase using methanol-chloroform $(1: 1 \mathrm{v} / \mathrm{v})$. Fatty acid methyl esters (FAME) were prepared 
from total lipids extracts using mild alkaline methanolysis (Guckert et al. 1985). Dried FAME samples were re-dissolved in $300 \mu \mathrm{L}$ chloroform (HPLC grade, Fisher Scientific) and analyzed by gas chromatography with mass spectrometry (GC-MS) on an Agilent 6890N gas chromatograph with a model 5973 inert mass selective detector (Agilent) fitted with an Agilent HP-5MS capillary column $(30 \mathrm{~m} \times 0.25 \mathrm{~mm}$ ID, $0.25 \mu \mathrm{m}$ film thickness; $\mathrm{J}+\mathrm{W}$ Scientific). Helium was used as the carrier gas with a temperature program of $130^{\circ} \mathrm{C}$ increasing at $3{ }^{\circ} \mathrm{C} \mathrm{min}^{-1}$ to $290{ }^{\circ} \mathrm{C}$ and held for $2 \mathrm{~min}$. Sample peaks were identified by comparison to Bacterial Acid Methyl Ester Mix standards (Supelco, Sigma Aldrich) or on the basis of mass spectra and expressed as a percentage of the total FAME quantified in each sample.

\section{Comparative analyses of three Kosmotoga spp. genomes}

The genome of $K$. olearia was compared to genomes of Kosmotoga sp. DU53 (accession number JFHK00000000) and $K$. arenicorallina (accession number JGCK00000000) (Pollo et al. 2016) using the IMG portal (Markowitz et al. 2014) and Geneious v.9. Specifically, genes were declared homologous if they were significantly similar in BLASTP and TBLASTN (Altschul et al. 1997) searches $\left(E\right.$ value $<10^{-3}$ ). For phylogenetic analyses, additional homologs of $K$. olearia genes were retrieved from the NCBI non-redundant $(n r)$ protein database and the IMG databases via BLASTP searches, retaining the 100 top-scoring matches with $E$ value $<10^{-3}$. Sequences were aligned using MAFFT (Katoh et al. 2002), and phylogenetic trees were reconstructed using RAxML (Stamatakis 2006), as implemented in Geneious v. 9. Homologs from the recently released genome of Kosmotoga pacifica (NZ_CP011232) (L'Haridon et al. 2014) were included in gene-specific phylogenetic analyses. Pairwise Average Nucleotide Identity (ANI) (Goris et al. 2007) was calculated using the Enveomics Toolbox (Rodriguez-R and Konstantinidis 2016).

\section{Detection of laterally transferred genes}

A customized version of HGTector (Zhu et al. 2014) (available through https://github.com/ecg-lab/hgtector) was used to identify putatively transferred protein-coding genes in the $K$. olearia genome. Homologs of each annotated protein-coding open reading frame (ORF) in the NC_012785 GenBank record were retrieved from a local copy of the NCBI $n r$ database (downloaded November 21, 2014) using the BLASTP program from BLAST 2.2.28+ (Altschul et al. 1997). Sequences were first filtered for low complexity regions using the seg algorithm. Then, only matches with $E$ value $<10^{-5}$ and sequence coverage $\geq 70 \%$ were retained. Database matches were expanded according to the MultispeciesAutonomousProtein2taxname file from RefSeq release
68. This was necessary as some genes across various taxonomic ranks were combined into a single entry in RefSeq, which artificially decreased the representation of these genes in Close and Distal groups (see below), and would confound downstream analysis. Taxonomic affiliation of each match was assigned using the NCBI Taxonomy database (downloaded on November 21, 2014). Only 500 top-scoring matches (after filtering for sequence coverage) were used as input for HGTector. The "Self" group was defined as TaxID 651456 (genus Kosmotoga), and the "Close" group was defined as either TaxID 1184396 (genus Mesotoga, a sister group) or TaxID 2419 (order Thermotogales, comprising Thermotoga, Mesotoga, and Kosmotoga). In either case, the "Distal" group comprised the remaining taxonomic groups. The conservative cutoff (the median between the zero peak and the first local minimum) was used for both the "Close" and "Distal" groups. A gene was designated as putatively transferred if its "Close" score was below the cutoff and its "Distal" score was above the cutoff. Putatively transferred genes with no top-scoring match in Thermotogae were designated as recent transfer events into K. olearia (labeled "K" in Table S8). Putatively transferred genes for which the difference between Close(Thermotoga) and Close(Mesotoga) scores was $<1$ were designated as gene transfer events into Kosmotogales (i.e., Kosmotoga and Mesotoga; labeled "K + M" in Table S8).

Acknowledgements This work was supported by a Research council of Norway award (Project no. 180444/V40) to C.L.N.; a Simons Investigator award from the Simons Foundation, a Dartmouth College Walter and Constance Burke Research Initiation Award (award no. 327936), and Dartmouth College start-up funds to O.Z.; and an Alexander Graham Bell Canada Graduate Scholarship CGS-M (Natural Sciences and Engineering Research Council of Canada) to S.M.J.P. We thank Rhianna Charchuk for technical assistance, Dr. Amanda J. Lohan for advice and discussion of RNA-Seq methodology, Dr. Karen Budwill for head-space gas analyses, and Jennifer Franks for initial discussions of lateral gene transfer detection methods.

Open Access This article is distributed under the terms of the Creative Commons Attribution 4.0 International License (http://creativecommons.org/licenses/by/4.0/), which permits unrestricted use, distribution, and reproduction in any medium, provided you give appropriate credit to the original author(s) and the source, provide a link to the Creative Commons license, and indicate if changes were made.

\section{References}

Akanuma G, Nanamiya H, Natori Y, Yano K, Suzuki S, Omata S, Ishizuka M, Sekine Y, Kawamura F (2012) Inactivation of ribosomal protein genes in Bacillus subtilis reveals importance of each ribosomal protein for cell proliferation and cell differentiation. $\mathbf{J}$ Bacteriol 194:6282-6291

Akanuma G, Kobayashi A, Suzuki S, Kawamura F, Shiwa Y, Watanabe S, Yoshikawa H, Hanai R, Ishizuka M (2014) Defect in the formation of $70 \mathrm{~S}$ ribosomes caused by lack of ribosomal protein L34 can be suppressed by magnesium. J Bacteriol 196:3820-3830 
Alreshidi MM, Dunstan RH, Macdonald MM, Smith ND, Gottfries J, Roberts TK (2015) Metabolomic and proteomic responses of Staphylococcus aureus to prolonged cold stress. J Proteom 121:44-55

Altschul SF, Madden TL, Schäffer AA, Zhang J, Zhang Z, Miller W, Lipman DJ (1997) Gapped BLAST and PSI-BLAST: a new generation of protein database search programs. Nucleic Acids Res 25:3389-3402

Baldridge KC, Contreras LM (2014) Functional implications of ribosomal RNA methylation in response to environmental stress. Crit Rev Biochem Mol Biol 49:69-89

Balleza E, López-Bojorquez LN, Martínez-Antonio A, ResendisAntonio O, Lozada-Chávez I, Balderas-Martínez YI, Encarnación S, Collado-Vides J (2009) Regulation by transcription factors in bacteria: beyond description. FEMS Microbiol Rev 33:133-151

Barria C, Malecki M, Arraiano CM (2013) Bacterial adaptation to cold. Microbiology 159:2437-2443

Boonyaratanakornkit BB, Simpson AJ, Whitehead TA, Fraser CM, El-Sayed NMA, Clark DS (2005) Transcriptional profiling of the hyperthermophilic methanarchaeon Methanococcus jannaschii in response to lethal heat and non-lethal cold shock. Environ Microbiol 7:789-797

Bordenave S, Chatterjee I, Voordouw G (2013) Microbial community structure and microbial activities related to $\mathrm{CO}_{2}$ storage capacities of a salt cavern. Int Biodeterior Biodegrad 81:82-87

Boucher Y, Douady CJ, Papke RT, Walsh DA, Boudreau MER, Nesbø CL, Case RJ, Doolittle WF (2003) Lateral gene transfer and the origins of prokaryotic groups. Annu Rev Genet 37:283-328

Buck M, Gallegos M, Studholme DJ, Guo Y, Gralla JD (2000) The bacterial enhancer-dependent $\sigma^{54}\left(\sigma^{\mathrm{N}}\right)$ transcription factor. J Bacteriol 182:4129-4136

Caspi R, Altman T, Billington R, Dreher K, Foerster H, Fulcher CA, Holland TA, Keseler IM, Kothari A, Kubo A, Krummenacker M, Latendresse M, Mueller LA, Ong Q, Paley S, Subhraveti P, Weaver DS, Weerasinghe D, Zhang P, Karp PD (2014) The MetaCyc database of metabolic pathways and enzymes and the BioCyc collection of pathway/genome databases. Nucleic Acids Res 42:D459-D471

Cho B, Zengler K, Qiu Y, Park YS, Knight EM, Barrett CL, Gao Y, Palsson BØ (2009) The transcription unit architecture of the Escherichia coli genome. Nat Biotechnol 27:1043-1049

Dahlsten E, Isokallio M, Somervuo P, Lindström M, Korkeala H (2014) Transcriptomic analysis of (group I) Clostridium botulinum ATCC 3502 cold shock response. PLoS One 9:e89958

de Mendoza D (2014) Temperature sensing by membranes. Annu Rev Microbiol 68:101-116

Dinsdale AE, Halket G, Coorevits A, van Landschoot A, Busse HJ, de Vos P, Logan NA (2011) Emended descriptions of Geobacillus thermoleovorans and Geobacillus thermocatenulatus. Int J Syst Evol Microbiol 61:1802-1810

DiPippo JL, Nesbø CL, Dahle H, Doolittle WF, Birkland N, Noll KM (2009) Kosmotoga olearia gen. nov., sp. nov., a thermophilic, anaerobic heterotroph isolated from an oil production fluid. Int $\mathrm{J}$ Syst Evol Microbiol 59:2991-3000

Dray S, Dufour AB, Chessel D (2007) The ade4 Package-II: two-table and K-table methods. R News 7:47-52

Duncan KE, Gieg LM, Parisi VA, Tanner RS, Tringe SG, Bristow J, Suflita JM (2009) Biocorrosive thermophilic microbial communities in Alaskan North Slope oil facilities. Environ Sci Technol 43:7977-7984

Duncan KE, Perez-Ibarra BM, Jenneman G, Harris JB, Webb R, Sublette $\mathrm{K}$ (2014) The effect of corrosion inhibitors on microbial communities associated with corrosion in a model flow cell system. Appl Microbiol Biotechnol 98:907-918
Faria JC, Demétrio CGB, Allaman IB (2013) bpca: Biplot of multivariate data based on principal components analysis. UESC and ESALQ, Ilheus

Foster PL (2007) Stress-induced mutagenesis in bacteria. Crit Rev Biochem Mol Biol 42:373-397

Fox GE (2010) Origin and evolution of the ribosome. Cold Spring Harb Perspect Biol 2:a003483

Galperin MY, Makarova KS, Wolf YI, Koonin EV (2015) Expanded microbial genome coverage and improved protein family annotation in the COG database. Nucleic Acids Res 43:D261-D269

Ghobakhlou A, Johnston A, Harris L, Antoun H, Laberge S (2015) Microarray transcriptional profiling of Arctic Mesorhizobium strain N33 at low temperature provides insights into cold adaption strategies. BMC Genom 16:383-396

Gittel A, Sørensen KB, Skovhus TL, Ingvorsen K, Schramm A (2009) Prokaryotic community structure and sulfate reducer activity in water from high-temperature oil reservoirs with and without nitrate treatment. Appl Environ Microbiol 75:7086-7096

Godin-Roulling A, Schmidpeter PAM, Schmid FX, Feller G (2015) Functional adaptations of the bacterial chaperone trigger factor to extreme environmental temperatures. Environ Microbiol 17:2407-2420

Godovikova V, Wang HT, Goetting-Minesky MP, Ning Y, Capone RF, Slater CK, Fenno JC (2010) Treponema denticola PrcB is required for expression and activity of the PrcA-PrtP (dentilisin) complex. J Bacteriol 192:3337-3344

Goris J, Konstantinidis KT, Klappenbach JA, Coenye T, Vandamme P, Tiedje JM (2007) DNA-DNA hybridization values and their relationship to whole-genome sequence similarities. Int J Syst Evol Microbiol 57:81-91

Graur D (2016) Prokaryotic genome evolution. In: Molecular and genome evolution. Sinauer Associates, Sunderland, pp 451-490

Guckert JB, Antworth CP, Nichols PD, White DC (1985) Phospholipid, ester-linked fatty acid profiles as reproducible assays for changes in prokaryotic community structure of estuarine sediments. FEMS Microbiol Lett 31:147-158

Haas BJ, Chin M, Nusbaum C, Birren BW, Livny J (2012) How deep is deep enough for RNA-Seq profiling of bacterial transcriptomes? BMC Genom 13:734-745

Kanehisa M, Goto S, Sato Y, Kawashima M, Furumichi M, Tanabe M (2014) Data, information, knowledge and principle: back to metabolism in KEGG. Nucleic Acids Res 42:D199-D205

Katoh K, Misawa K, Kuma K, Miyata T (2002) MAFFT: a novel method for rapid multiple sequence alignment based on fast Fourier transform. Nucleic Acids Res 30:3059-3066

Kotlar HK, Lewin A, Johansen J, Throne-Holst M, Haverkamp T, Markussen S, Winnberg A, Ringrose P, Aakvik T, Ryeng E, Jakobsen K, Drabløs F, Valla S (2011) High coverage sequencing of DNA from microorganisms living in an oil reservoir 2.5 kilometres subsurface. Environ Microbiol Rep 3:674-681

Latif H, Lerman JA, Portnoy VA, Tarasova Y, Nagarajan H, SchrimpeRutledge AC, Smith RD, Adkins JN, Lee D, Qiu Y, Zengler K (2013) The genome organization of Thermotoga maritima reflects its lifestyle. PLoS Genet 9:e1003485

L'Haridon S, Jiang L, Alain K, Chalopin M, Rouxel O, Beauverger M, Xu H, Shao Z, Jebbar M (2014) Kosmotoga pacifica sp. nov., a thermophilic chemoorganoheterotrophic bacterium isolated from an East Pacific hydrothermal sediment. Extremophiles 18:81-88

López-García P, Zivanovic Y, Deschamps P, Moreira D (2015) Bacterial gene import and mesophilic adaptation in archaea. Nat Rev Microbiol 13:447-456

Makarova KS, Aravind L, Wolf YI, Koonin EV (2011) Unification of Cas protein families and a simple scenario for the origin and evolution of CRISPR-Cas systems. Biol Direct 6:38-65

Markowitz VM, Chen IA, Palaniappan K, Chu K, Szeto E, Pillay M, Ratner A, Huang J, Woyke T, Huntemann M, Anderson I, Billis 
K, Varghese N, Mavromatis K, Pati A, Ivanova NN, Kyrpides NC (2014) IMG 4 version of the integrated microbial genomes comparative analysis system. Nucleic Acids Res 42:D560-D567

Mega R, Manzoku M, Shinkai A, Nakagawa N, Kuramitsu S, Masui R (2010) Very rapid induction of a cold shock protein by temperature downshift in Thermus thermophilus. Biochem Biophys Res Commun 399:336-340

Mykytczuk NCS, Foote SJ, Omelon CR, Southam G, Greer CW, Whyte LG (2013) Bacterial growth at $-15^{\circ} \mathrm{C}$; molecular insights from the permafrost bacterium Planococcus halocryophilus Or1. ISME J 7:1211-1226

Nanavati DM, Thirangoon K, Noll KM (2006) Several archaeal homologs of putative oligopeptide-binding proteins encoded by Thermotoga maritima bind sugars. Appl Environ Microbiol 72:1336-1345

Nesbø CL, Kumaraswamy R, Dlutek M, Doolittle WF, Foght J (2010) Searching for mesophilic Thermotogales bacteria: "Mesotogas" in the wild. Appl Environ Microbiol 76:4896-4900

Nesbø CL, Swithers KS, Dahle H, Haverkamp TH, Birkeland N, Sokolova T, Kublanov I, Zhaxybayeva O (2015) Evidence for extensive gene flow and Thermotoga subpopulations in subsurface and marine environments. ISME J 9:1532-1542

Nunoura T, Hirai M, Imachi H, Miyazaki M, Makita H, Hirayama H, Furushima Y, Yamamoto H, Takai K (2010) Kosmotoga arenicorallina sp. nov. a thermophilic and obligately anaerobic heterotroph isolated from a shallow hydrothermal system occurring within a coral reef, southern part of the Yaeyama Archipelago, Japan, reclassification of Thermococcoides shengliensis as Kosmotoga shengliensis comb. nov., and emended description of the genus Kosmotoga. Arch Microbiol 192:811-819

Oko BJ, Tao Y, Stuckey DC (2017) Dynamics of two methanogenic microbiomes incubated in polycyclic aromatic hydrocarbons, naphthenic acids, and oil field produced water. Biotechnol Biofuels 10:123

Phadtare S (2004) Recent developments in bacterial cold-shock response. Curr Issues Mol Biol 6:125-136

Phadtare S, Hwang J, Severinov K, Inouye M (2003) CspB and CspL, thermostable cold-shock proteins from Thermotoga maritima. Genes Cells 8:801-810

Piette F, D’Amico S, Struvay C, Mazzucchelli G, Renaut J, Tutino ML, Danchin A, Leprince P, Feller G (2010) Proteomics of life at low temperatures: trigger factor is the primary chaperone in the Antarctic bacterium Pseudoalteromonas haloplanktis TAC125. Mol Microbiol 76:120-132

Pollo SMJ, Zhaxybayeva O, Nesbø CL (2015) Insights into thermoadaptation and the evolution of mesophily from the bacterial phylum Thermotogae. Can J Microbiol 61:655-670

Pollo SMJ, Charchuk R, Nesbø CL (2016) Draft genome sequences of Kosmotoga sp. strain DU53 and Kosmotoga arenicorallina S304. Genome Announc 4:e00570-16

Pysz MA, Ward DE, Shockley KR, Montero CI, Conners SB, Johnson MR, Kelly RM (2004) Transcriptional analysis of dynamic heatshock response by the hyperthermophilic bacterium Thermotoga maritima. Extremophiles 8:209-217

Qiu Y, Cho BK, Park YS, Lovley D, Palsson B, Zengler K (2010) Structural and operational complexity of the Geobacter sulfurreducens genome. Genome Res 20:1304-1311

Raghubeer EV, Matches JR (1990) Temperature range for growth of Escherichia coli serotype 0157:H7 and selected coliforms in E. coli medium. J Clin Microbiol 28:803-805
Ratkowsky DA, Lowry RK, McMeekin TA, Stokes AN, Chandler RE (1983) Model for bacterial culture growth rate throughout the entire biokinetic temperature range. J Bacteriol 154:1222-1226

Robinson MD, Smyth GK (2008) Small-sample estimation of negative binomial dispersion, with applications to SAGE data. Biostatistics 9:321-332

Rodriguez-R LM, Konstantinidis KT (2016) The enveomics collection: a toolbox for specialized analyses of microbial genomes and metagenomes. Peer J Prepr 4:e19001

Schumann W (2009) Temperature sensors of eubacteria. Adv Appl Microbiol 67:213-256

Schut GJ, Boyd ES, Peters JW, Adams MWW (2012) The modular respiratory complexes involved in hydrogen and sulfur metabolism by heterotrophic hyperthermophilic archaea and their evolutionary implications. FEMS Microbiol Rev 37:182-203

Sievert S, Vetriani C (2012) Chemoautotrophy at deep-sea vents: past, present, and future. Oceanography 25:218-233

Stamatakis A (2006) RAxML-VI-HPC: maximum likelihood-based phylogenetic analyses with thousands of taxa and mixed models. Bioinformatics 22:2688-2690

Swinnen IAM, Bernaerts K, Dens EJJ, Geeraerd AH, Van Impe JF (2004) Predictive modelling of the microbial lag phase: a review. Int J Food Microbiol 94:137-159

Swithers KS, DiPippo JL, Bruce DC, Detter C, Tapia R, Han S, Goodwin LA, Han J, Woyke T, Pitluck S, Pennacchio L, Nolan M, Mikhailova N, Land ML, Nesbø CL, Gogarten JP, Noll KM (2011) Genome sequence of Kosmotoga olearia strain TBF 19.5.1, a thermophilic bacterium with a wide growth temperature range, isolated from the Troll B oil platform in the North Sea. J Bacteriol 193:5566-5567

Takai K, Nakamura K, Toki T, Tsunogai U, Miyazaki M, Miyazaki J, Hirayama H, Nakagawa S, Nunoura T, Horikoshi K (2008) Cell proliferation at $122{ }^{\circ} \mathrm{C}$ and isotopically heavy $\mathrm{CH}_{4}$ production by a hyperthermophilic methanogen under high-pressure cultivation. Proc Natl Acad Sci USA 105:10949-10954

Vigneron A, Alsop EB, Lomans BP, Kyrpides NC, Head IM, Tsesmetzis N (2017) Succession in the petroleum reservoir microbiome through an oil field production lifecycle. ISME J 11:2141-2154

Wang Z, Tong W, Wang Q, Bai X, Chen Z, Zhao J, Xu N, Liu S (2012) The temperature dependent proteomic analysis of Thermotoga maritima. PLoS One 7:e46463

Zhaxybayeva O, Swithers KS, Lapierre P, Fournier GP, Bickhart DM, DeBoy RT, Nelson KE, Nesbø CL, Doolittle WF, Gogarten JP, Noll KM (2009) On the chimeric nature, thermophilic origin, and phylogenetic placement of the Thermotogales. Proc Natl Acad Sci USA 106:5865-5870

Zhaxybayeva O, Swithers KS, Foght J, Green AG, Bruce D, Detter C, Han S, Teshima H, Han J, Woyke T, Pitluck S, Nolan M, Ivanova N, Pati A, Land ML, Dlutek M, Doolittle WF, Noll KM, Nesbø CL (2012) Genome sequence of the mesophilic Thermotogales bacterium Mesotoga prima MesG1.Ag.4.2 reveals the largest Thermotogales genome to date. Genome Biol Evol 4:700-708

Zhu Q, Kosoy M, Dittmar K (2014) HGTector: an automated method facilitating genome-wide discovery of putative horizontal gene transfers. BMC Genom 15:717 